\title{
Methodic Techniques of Solving Technical Problems Developing Technical Students' Thinking
}

\author{
Zyamil G. Nigmatov ${ }^{1}$ \\ ${ }^{1}$ Kazan (Volga region) federal university, Kazan, Russia \\ Correspondence: Zyamil G. Nigmatov, Kazan (Volga region) federal university, Kremlevskaya Street 18, Kazan, \\ 420008, Russia.
}

Received: October 24, 2014 Accepted: December 3, 2014 Online Published: December 18, 2014

doi:10.5539/res.v7n1p171 URL: http://dx.doi.org/10.5539/res.v7n1p171

\begin{abstract}
The purpose of this article is to review some of the instructional techniques of solving technical problems developing technical thinking of students, which are based on the objective laws of the development of the properties of the modern school, focused on a student who is prone to technical activities. The article reveals the leading approaches (processual, cognitive-evaluative) to the concept of "technical thinking" as well as the content of the process of development of technical students' thinking at senior secondary schools, it is proved that the solution of technical problems is one of the most effective methods of developing technical students' thinking, it is justified that discussed methodic techniques of solving technical problems do not create obsessive, annoying algorithms requiring a lot of patience; they stimulate students' interest to these problems, encourage them to a wide search and cognitive activity. The system of such methods is based on the objective laws of mental development of student's personality prone to technical activities. In general, the results of experiments to solve technical problems show that, on the one hand, they stimulate the development of technical thinking of students, on the other, they increase general labor educatedness. The stuff of this article may be useful for teachers of technology, physics, mathematics, as well as at career development courses.
\end{abstract}

Keywords: technical thinking, technical competence, development, technical problem, solving

\section{Introduction}

Active reform process in social and economic spheres of society put the theory and practice of forming technical competence at the forefront. In recent decades, “... many companies are using the concept of "competence". These are integrated knowledge, skills, judgment and attributes that are needed for people to carry out the work effectively "(Developing a Competency Framework, 1992). These processes made us to analyze the established theory and practical technologies of training and education. And for such a versatile analysis it's important to develop students' technical competence, especially high school students' one. Except that "the development of technical competencies in terms of learning should be based on the decision in different interesting formats of technical or physical problems that accompany the process of school students training at all stages of entry into the profession" (Nugumanova, 2010).

As "functional or, as they are called, technical competences concern to the functions, processes ... and include the knowledge, skills and practices needed for successful specific job or task performing" (Skills vs Competencies. What's the Difference, 2012), so solving entertaining technical problems is becoming the norm at school and stands high in the system of development technology of technical students' thinking. In the age of technological progress it is important to educate tech-savvy, deeply thinking people "who are very practical, technical and accurate. These thinkers rely heavily on common sense, not imagination. Perhaps that's why people prefer to call them 'technical thinkers', their work can be thought out in details and deserves all-round support" (Different Ways of Thinking, 2014).

The importance of technical thinkers at school lies in the fact that the technical thinking is one of the basic conditions of polytechnic education and vocational guidance. It contributes to children' sustained interest in engineering, development of innovative and inventive inclinations, promotes the development of scientific education level. 


\section{Methodological Framework}

It turns out that technical thinking is carried out by using well-known mental operations which are based on theoretical methods of scientific research - analysis, synthesis, comparison, generalization, etc., but their flow has a special focus, i.e. technical thinking can be theoretical and practical, reproductive and productive, imaginative and visual active, depending on the problems.

\section{Results}

\subsection{The Technical Problems as a Method and Result of Technical Thinking Development}

Many scientists and teacher-practicians emphasize that technical thinking is manifested in the ability to successful solving of technical problems, so the most logical way is to highlight the ability of solving complex technical problems of different levels of complexity as the criterion of students' technical thinking formation. Under such problems, we understand the technical/ technological task, the solution of which requires knowledge of all the components that make up technical thinking. One can judge the level of technical thinking development according to the success in solving of complex technical problems of various difficulties.

Since under the technical they understand a set of intellectual processes and their results, which provide the solution of problems of vocational activities, and from this point of view, the main function of technical thinking is the solution of technical/technological problems. The following three instructional techniques are characteristic for their solution: first, the definition of the goal, the desire to get an answer to this question; secondly, the need to understand the essence of the existing conditions, initial data and take them into account; thirdly, the use of those methods of problems solving, which correspond to existing conditions and initial data.

The development of technical thinking is possible on the following methodic algorithm: at the first lessons the teacher shows how to solve typical technical problems, and then propose to solve them themselves. In the next step the students are offered simple, but non-standard technical problems, while showing technical thinking techniques, such as search for analogies, combination, various types of substitutions and etc. As a rule, students respond to unusual logical steps and are enthusiastic in solving such problems. Ways to solve any problems, not only a constructive or technological one, are based on the application of general principles and guidelines in these circumstances, summing up a special case under the general rule.

\subsection{Methodic Techniques of Solving Technical Problems}

General guidelines for students on non-standard problems can be expressed as:

1) When solving such problems try to understand the technical meaning of all data. Seek and consider different ways of solving problems, do not ignore any even one would seem an absurd decision. Any technical task is graphically displayed, so make various sketches. Do not hesitate to ask the teacher any questions about the task.

2) As soon as you understand the "technical" sense of the task, look for analogies, try to find an algorithm of task designing, combine. You can search for a solution "to chance", i.e. as they say, that came to mind. These recommendations are given to students depending on the current situation in the course of task solving. Development of technical thinking is possible with the help of training each reception.

Conditions and initial data of technological problems are not always given in the completed form; a lot of them one has to find independently, to determine the sufficiency of this data for the task solving. However, the greatest difficulties are related to the ways of task solving. It is known that solutions of any problem are based on the use of general principles in particular condition, on summing up a special case under the general rule.

Let us look at the most effective, in our view, teaching methods of solving technical problems which contributing to the development of technical students' thinking and, consequently, the formation of their technical competence.

One of them is the method of working out strategies for search analogies, which consists of initial explanation the essence of analogies search, their types and features of mental activity. Then the student answers the questions: "How can you explain the similar solutions?"; "What does the search for analogy mean?"; "What technical analogies do you know?" Answers to these questions will help to diagnose the theoretical readiness of students to technical problems solution of a certain type. Satisfactory readiness is supported by demonstration the solution of a specific task (team or individual) with a detailed analysis of the solution. After students' independent solutions of technical/technological problems they answer the other questions: "What analogies have you seen?"; "Why have you chosen this analogy?"; "What difficulties have you experienced while searching for analogies?" The answers to these questions allow to give individual recommendations on choosing a strategy for solving technical problems, which develop thinking extensively and, as a result, bringing the 
field-specific interest and forming the basic competences.

Later the algorithm is repeated on complicating trajectory and encouraged to use more unusual and unexpected analogies. As a result, it is proposed a competitive task that requires a deep judgment, and the judgment "makes a decision reasonable, based more on facts but not emotions, analyzes problems skillfully, uses logic for reaching a solution" (Shippmann et al., 2000).

Meaningfully the development of technical thinking when considering the method of analogies is as follows: initially, the students are explained that the search analogies technique is based on the establishment of significant similarities between structures, functions and principles of operation of any technical device or devices, indicated in the task with a non-technical object (insects, animals, etc.). The establishment of similarity between them gives a hint at transition of the corresponding structure, function, principle of operation into the search for task solution. They distinguish a complete or obvious analogy, significant, hidden or part-time, on the individual nodes. The complete analogy practically means the coincidence of structures, functions, that makes it possible to transfer a known solution of the analogy to the original one.

For students of the modern school this method of analogies classification, as a rule, is quite interesting and quite affordable. During this method of analogies training the methods of combining and remodeling are often used. The students' reasoning is built on the principle of not strict logic, but considering options of real use one or the other technical unit. The main thing is "to be able to analyze information quickly and use it in order to obtain reliable solutions" (What skills and competencies do you need for a career in HR, 2014). Thus, it is necessary to liberate thinking, focus attention on formation the strategy of solutions, achieving the result, logic vision of technical thinking universality.

Realizing that the "problems faced by people involved in engineering (its design, construction, maintenance, repair, etc.) have some specific features in comparison with problems solved in other areas" (Dushkov, 2005), in the stock of problems on development technical thinking it is used the "random settings" strategy. This strategy does not even have any example of the algorithm, so its purpose is to teach one's own thinking not to give up in dead-end situations. In the simplest variant the method of "random settings" is that the student is suggested to try any logical step that comes to his/her head in case of obstacles in solving the technical task, to fix the random images, objects, principles and try to "adapt" to the task solution.

The strategy of "time constraints" significantly develops technical thinking, the meaning of which is to support the well-known psychological phenomenon when human mental activity begins to be activated under time pressure. It should be noted that the solution to a technical problem in free time mode, as a rule, stimulates the student to search several possible solutions, under time pressure the mental activity is aimed at finding a single optimal solution. It is important to indicate the didactic pattern: if students have actualized strong knowledge, they find quickly the solution to the time; if strong knowledge is not acquired by students at the level of free application, so they reduce any results, or face mental block and refuse to solve the task. This suggests that interesting actualizing education activity should introduce the solution of non-standard technical problems, as only a positive result has an educational effect and develops technical competence.

"It is difficult to know for sure today what competencies will be in demand in five years. We must not forget that in addition to technical competence other types of skills and knowledge are also important in the career" (Developing a Competency Framework, 1992). Therefore, the specific feature of technical thinking development of high school students in the condition of information security is the combination of technical problems solutions in the mode "teacher-student" and "computer software - student - teacher."

In a number of factors in the development of technical thinking it may be included the method of sudden prohibitions, the meaning of which is in limitation of possible solutions of technical task (for example, in the problem of kinematics there is a restriction on the use of certain transfer types). Such an approach to the technical task solution is often original, as stimulates the search of new solution for a well-known technical device. Although the "unnecessary restrictions is another very common barrier that people face when trying to solve the problem ...", but "this phenomenon occurs when an object is trying to solve the problem subconsciously sets limits on the task, which in turn makes him/ her to strain in order to be more innovative in his/her thinking" (Altshuller, 1973).

Using the method of sudden prohibitions in solving technical problems during the students' course of studies enhances the amplitude expansion of individual style of technical activities. It is fair to say, that the techniques of non-standard methods of mental activities during their adoption in the process of training pass into not just personal quality, but become the characteristic of professional competence. 
Following a particularly effective method of solving technical problems developing technical students' thinking are brainstorming techniques - this is an operational method for solving the problem based on the stimulation of creative activity in which the participants express the greatest number of technical problems solutions, including the most fantastic. Then, from the total number of expressed ideas they select the most successful ones, which can be used in practice. This method, developed by Alex Osborn in 1953, based on the assumption that one of the main obstacles for creation new ideas is the "fear of evaluation": even the high school students, often do not express aloud interesting imaginative ideas for fear of meeting with skeptical attitude from their teachers and classmates. The purpose of brainstorming is to except an evaluative component. Classical Osborn's technique of brainstorming is based on two fundamental principles - "the idea of delaying the verdict" and "quantity is transformed into quality". By the way "brainstorming" provides free and open environment that encourages everyone to participate. Fancy ideas are welcome, and all participants are fully encouraged when they contribute to developing a rich choice of creative solutions" (Brainstorming, 2014). It is necessary to ensure that between the parties of "attack" there were established friendly relations. Unacceptable: smirk, omissions, skeptical smile, criticisms, etc. The ideas expressed by one of the participants may be supported by others (Methods for solving new creative challenges, 2014).

It is understood that the above methods can be applied only by that teacher who can use them, who can take into account the personal intellectual potential learner (Kalimullin, 2014). Otherwise, you can achieve the opposite effect - the total rejection of this type of activity.

Thus, as the main educational impact developing students' technical thinking in the school we used the solution of technical problems of various types and degrees of complexity. We believed that the result of the successful formation of technical students' thinking should be the successful solution of technical problems, because in the process of solving students demonstrate the creative nature - criticism, efficiency and reflexivity. Focusing on these features allows to make the process of technical thinking formation diagnosed (Zanfirova, 2008).

When solving rather complicated and complex technical problems school teachers and their students use a variety, sometimes unconventional, of the most incredible techniques and solutions. In this article, we gave examples of some of them.

\section{Discussions}

\subsection{The Debate over the Definition "Technical Thinking"}

Most researchers note that the development of technical thinking is a complex process which flows usually quite slow and depends on general intelligence, skills, abilities to technical thinking and other factors. In our opinion, technical thinking skills are acquired by people as a result of long-term practice. But it's important to begin development of these skills since early ages, supporting their development in the junior, then in the middle and high school. In the result of multiple repetitions students accumulate experience and develop a habit of technical thinking (Planida, 2010). Thanks to technology lessons, where technological problems are mostly solved, the possibility of developing students' technical thinking increases many times, they acquire skills, abilities, knowledge in technical field at such lessons. Therefore it is necessary to pay serious attention to this aspect.

\section{Conclusion}

All methodic techniques discussed here have a common "goal to create conditions for developing spirituality; a business-like, socially adapted and creative person possesses knowledge of the general and technical culture, technical thinking and ability to exist harmonically in the condition of "man and nature"," man-equipment", "man-man" (Planida, 2010).

Studies show that, firstly, the system of such methods is based on the objective laws of mental development of the students' personality prone to technical activities; secondly, these techniques do not create obtrusive, annoying, algorithms requiring a lot of patience for the solution, so they only stimulate the form of interest, encourage broad search and cognitive activity that actually characterizes not only the level of demanding on equipment and technical competencies, but also general students' educatedness. It should be recognized that the "technical and technological skills are a part of large human activity and are essential for the survival of humanity" (Planida, 2010).

Thus, if they include in components of technical thinking such aspects as divergence, criticism and reflexivity, they are poorly developed, it can serve as scientific thinking. Moreover, its specific features appear in the solution of rather complicated and complex technical problems and caused by their originality. 


\section{Recommendations}

As can be seen from the contents of the article, this material will be useful especially for teachers of technology, since taking into account presented here instructional techniques and other indicators will allow them to assess objectively the successful solving of complex technical problems and to determine the level of development of technical students' thinking.

\section{References}

Altshuller, G. (1973). Innovation Algorithm. Worcester, MA: Technical Innovation Center.

Brainstorming. (2014). Generating. Many Radical, Creative Ideas.

Different Ways of Thinking. (2014). http://personalitycafe.com/nts-temperament-forum-intellects /45618-different-ways-thinking.html

Dushkov, B. A., Korolev, A. V., \& Smirnov, B. A. (2005). Encyclopedic dictionary, Labor Psychology, Management, Engineering Psychology and Ergonomics.

Kalimullin, A. M. (2014). Processes of reforming teacher training in modern Russia (experience of the Kazan federal university). World Applied Sciences Journal, 30(4), 447-450.

Nugumanova, L. N. (2010). Labor education in professional school by means of technical competence development. Teacher's Education and Science, 6, 76-80.

Planida, S. (2010). Didactic conditions for vocational thinking formation of secondary specialized college students (Ph.D. thesis, Armavir State Pedagogical University).

Shippmann, J. S., Ash, R. A., Battista, M., Carr, L., Eyde, L. D., Hesketh, B., ... Sanchez, J. I. (2000). The practice of competency modeling. Personnel Psychology, 53, 703-740.

What skills and competencies do you need for a career in HR? (2014). http://targetjobs.co.uk/career-sectors/hr-and-recruitment/324027-what-skills-and-competencies-do-you-need -for-a-career-in-hr

Zanfirova, L. (2008). Formation of technical thinking in the process of preparation of agroengineering university students (PhD thesis, Moscow State Agro-Engineering University).

\section{Copyrights}

Copyright for this article is retained by the author(s), with first publication rights granted to the journal. This is an open-access article distributed under the terms and conditions of the Creative Commons Attribution license (http://creativecommons.org/licenses/by/3.0/). 